\title{
Thermal stability of $\boldsymbol{N}$-heterocycle-stabilized iodanes - a systematic investigation
}

\author{
Andreas Boelke ${ }^{\ddagger 1}$, Yulia A. Vlasenko ${ }^{\ddagger 2}$, Mekhman S. Yusubov², Boris J. Nachtsheim ${ }^{* 1}$ \\ and Pavel S. Postnikov ${ }^{\star 2,3}$
}

\author{
Full Research Paper \\ Address: \\ ${ }^{1}$ Institute for Organic and Analytical Chemistry, University of Bremen, \\ 28359 Bremen, Germany, ${ }^{2}$ Research School of Chemistry and \\ Applied Biomedical Sciences, Tomsk Polytechnic University, 634050 \\ Tomsk, Russian Federation and ${ }^{3}$ Department of Solid State \\ Engineering, University of Chemistry and Technology, 16628 Prague, \\ Czech Republic \\ Email: \\ Boris J. Nachtsheim* - nachtsheim@uni-bremen.de; \\ Pavel S. Postnikov* - postnikov@tpu.ru \\ * Corresponding author $\ddagger$ Equal contributors \\ Keywords: \\ differential scanning calorimetry; hypervalent iodine; $N$-heterocycle; \\ stability; thermogravimetry

\begin{abstract}
Beilstein J. Org. Chem. 2019, 15, 2311-2318.
\end{abstract} \\ doi:10.3762/bjoc. 15.223 \\ Received: 23 July 2019 \\ Accepted: 20 September 2019 \\ Published: 27 September 2019 \\ Associate Editor: I. Baxendale \\ (c) 2019 Boelke et al.; licensee Beilstein-Institut. \\ License and terms: see end of document.
}

\section{Abstract}

The thermal stability of pseudocyclic and cyclic $N$-heterocycle-stabilized (hydroxy)aryl- and mesityl(aryl)- $\lambda^{3}$-iodanes (NHIs) through thermogravimetric analysis (TGA) and differential scanning calorimetry (DSC) is investigated. Peak decomposition temperatures $\left(T_{\text {peak }}\right)$ were observed within a wide range between 120 and $270{ }^{\circ} \mathrm{C}$. Decomposition enthalpies $\left(\Delta H_{\text {dec }}\right)$ varied from -29.81 to $141.13 \mathrm{~kJ} / \mathrm{mol}$. A direct comparison between pseudocyclic and cyclic NHIs revealed high $T_{\text {peak }}$ but also higher $\Delta H_{\text {dec }}$ values for the latter ones. NHIs bearing $N$-heterocycles with a high N/C-ratio such as triazoles show among the lowest $T_{\text {peak }}$ and the highest $\Delta H_{\text {dec }}$ values. A comparison of NHIs with known (pseudo)cyclic benziodoxolones is made and we further correlated their thermal stability with reactivity in a model oxygenation.

\section{Introduction}

Hypervalent iodine compounds, in particular aryl- $\lambda^{3}$-iodanes, have found wide spread applications as oxidants and electrophilic group transfer reagents in organic synthesis [1-11]. A 3 -center 4-electron bond connects the central iodine atom, providing two electrons, with two carbon- or heteroatom ligands $\mathrm{L}^{1}$ and $\mathrm{L}^{2}$, providing one electron each (Figure 1). These ligands can be arranged along the hypervalent iodine atom through an open-chained, a pseudocyclic or a cyclic structure.
One of the ligands gets either substituted during an iodanemediated transformation or is directly transferred in an electrophilic group-transfer reaction onto a nucleophilic substrate. The other ligand stabilizes the electrophilic hypervalent iodine atom in its ground state or directly influences its reactivity by stabilizing reactive intermediates or transition states. In recent years, a plethora of cyclic and pseudocyclic iodanes have been developed with covalently attached stabilizing ligands $\mathrm{L}^{2}$ and 


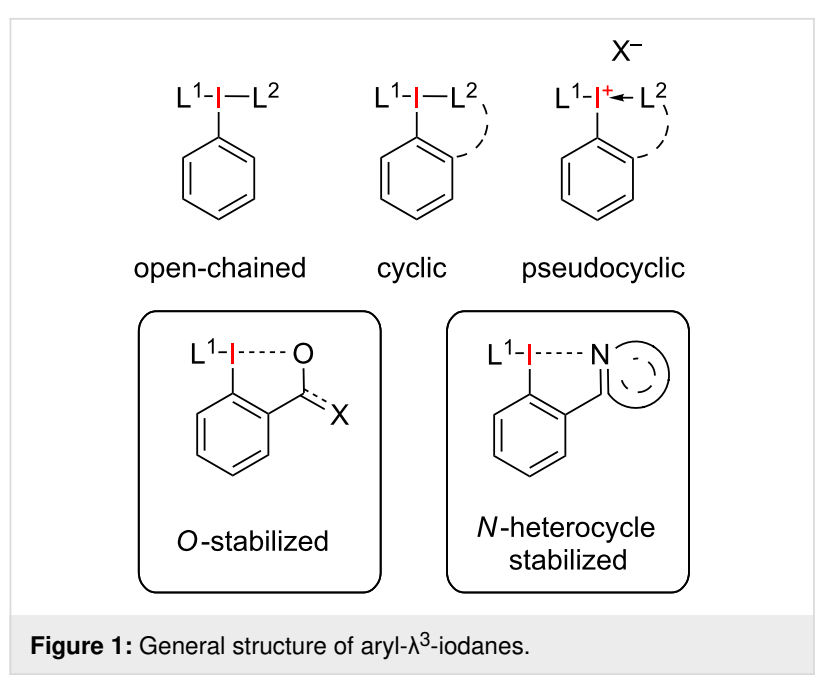

applied in a variety of group-transfer reactions. Prominent examples include ethynyl benziodoxolones (EBX, $\mathrm{L}^{1}=$ alkyne) [12], the Zhdankin reagent azidobenziodoxole $\left(A B X, L^{1}=N_{3}\right)$ [13], cyanobenziodoxole $\left(\mathrm{CBX}, \mathrm{L}^{1}=\mathrm{CN}\right)$ [14] or Togni's reagent $\left(\mathrm{L}^{1}=\mathrm{CF}_{3}\right)$ [15]. Even though the transferable ligand $\left(\mathrm{L}^{1}\right)$ has been varied extensively, the chemical design of the stabilizing donor ligand $\mathrm{L}^{2}$ has not been investigated as intensive. In general, carboxylic acid derivatives, ethers or free alcohols are utilized to stabilize the hypervalent iodine center by an oxygen-iodine bond or through dative oxygen-iodine interactions in (pseudo)cyclic iodanes. Albeit aryl- $\lambda^{3}$-iodanes are viewed as safe and stable under ambient temperatures, systematic thermal degradation studies of hypervalent iodine reagents are still rare. In 1992 Varvoglis and co-workers investigated the thermal degradation of a variety of aryl iodine(III) dicarboxylates into alkyl and aryl radicals through thermogravimetry [16,17]. In 2013 Kumar and co-workers compared the thermal properties of open-chained aryl- $\lambda^{3}$-iodanes with their polymer bound derivatives and found an endothermic decomposition behavior [18]. In the same year Haller and co-workers investigated the explosive properties of Togni's reagent and very recently, Williams and co-workers analyzed the sensitivity of common oxidants including 2-iodoxybenzoic acid (IBX) and Dess-Martin periodinane (DMP) [19,20]. Waser and co-workers examined the thermal stability of the Zhdankin reagent $A B X$ and compared it with the amide-stabilized derivative ABZ (azidobenziodazolone). They found a remarkable higher thermal stability of the latter compound by DSC analysis indicated by a higher onset temperature and a lower heat release during decomposition [21]. ABZ is a rare example of a nitrogen-stabilized iodane, showing promising properties in terms of reactivity and stability. However, iodanes stabilized by nitrogen-based ligands, in particular $N$-heterocycles are still underexplored [22-28]. Recently, our groups investigated systematically cyclic and pseudocyclic $N$-heterocycle-stabi- lized iodanes (NHIs). We demonstrated that the $N$-heterocycle significantly influences the important $\mathrm{I}-\mathrm{L}^{1}$ bond length and subsequently has a profound impact on the reactivity of the iodane in oxygen transfer reactions [29,30]. Since the combination of a highly oxidized hypervalent iodine species with $\mathrm{N}$-heterocycles with a high N/C-ratio might result in potential hazardous high energy materials, we herein investigated their thermal stability by thermogravimetric analysis (TGA) and differential scanning calorimetry (DSC).

\section{Results and Discussion}

We started our experiments with the preparation of appropriate $\lambda^{3}$-iodanes bearing $\mathrm{N}$ - and $\mathrm{O}$-centered ligands according to our reported procedures $[29,30]$. The synthesized compounds then have been divided in the following discussion by their principle structural features into pseudocyclic and cyclic hydroxy(phenyl)- $\lambda^{3}$-iodanes (Figure 2) and pseudocyclic and cyclic mesityl(phenyl)- $\lambda^{3}$-iodanes (Figure 6).

We initially investigated the thermal decomposition of $N$-heterocycle-stabilized pseudocyclic (hydroxy)aryl iodanes 2-15 (Figure 2 and Table S1, Supporting Information File 1). As the model oxygen-stabilized derivative, we evaluated the thermal decomposition behavior of pseudocyclic iodosobenziodoxolone $\mathbf{1}$. The decomposition of $\mathbf{1}$ has a two-step character and includes initial endothermic melting at $185.1^{\circ} \mathrm{C}$ followed by exothermal decomposition at $206.8{ }^{\circ} \mathrm{C}$ with an $\Delta H_{\mathrm{dec}}$ of $72.9 \mathrm{~kJ} / \mathrm{mol}$ (Figure 3a). For the pseudocyclic NHI 2 with a triazole ligand no initial melting process was detected. Instead the solid degraded with a pronounced and narrow (less than $1^{\circ} \mathrm{C}$ ) exothermal peak at $120.8{ }^{\circ} \mathrm{C}$ (Figure $3 \mathrm{~b}$ ). Decomposition was associated with a higher $\Delta H_{\mathrm{dec}}$ of $116.3 \mathrm{~kJ} / \mathrm{mol}$.

A similar decomposition behavior was observed for the other triazole-containing pseudocyclic NHIs 3-5. Introduction of a methyl-substituent at $\mathrm{C} 5$ of the triazole $\mathbf{3}$ was accompanied by an increased decomposition enthalpy $\left(\Delta H_{\mathrm{dec}}=125.1 \mathrm{~kJ} / \mathrm{mol}\right)$. However, thermal stability as indicated by a higher $T_{\text {peak }}$, significantly increased. Methyl substitution at N2 resulted in an even higher $T_{\text {peak }}$ at $152.4{ }^{\circ} \mathrm{C}$ and a decreased decomposition enthalpy. If the triazole is connected to the iodoarene via $\mathrm{N} 1$ as in $5, T_{\text {peak }}$ decreases and $\Delta H_{\text {dec }}$ increases. It should be concluded that triazole $\mathbf{4}$ has the most advantageous decomposition behavior: It is thermally the most stable among the pseudocyclic triazoles with the lowest $\Delta H_{\mathrm{dec}}$ value. However, even the triazoles $\mathbf{2}, \mathbf{3}$, and $\mathbf{5}$ can be considered as safe compounds, but still deserve a common precaution due to the narrow decomposition process.

Pyrazoles 6 and 7 are thermally more stable $\left(T_{\text {peak }}=168.9\right.$ and $196.5^{\circ} \mathrm{C}$ ) with a remarkably lower $\Delta H_{\mathrm{dec}}$ value. NH-pyrazole 6 
pseudocyclic hydroxy(phenyl)- $\lambda^{3}$-iodanes<smiles>C[I+](O)([Se-])c1ccccc1C(=O)O</smiles>

$1,206.8^{\circ} \mathrm{C}$, $72.93 \mathrm{~kJ} / \mathrm{mol}$

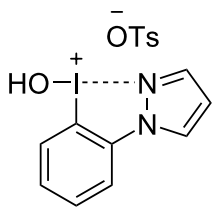

$7,196.5^{\circ} \mathrm{C}$, $50.78 \mathrm{~kJ} / \mathrm{mol}$<smiles></smiles>

2, $120.8^{\circ} \mathrm{C}$, $116.28 \mathrm{~kJ} / \mathrm{mol}$<smiles></smiles>

$3,143.6^{\circ} \mathrm{C}$, $125.11 \mathrm{~kJ} / \mathrm{mol}$<smiles>Cn1ncc(-c2ccccc2[I-]([O+])([O-])O)n1</smiles>

4, $152.4^{\circ} \mathrm{C}$, $88.76 \mathrm{~kJ} / \mathrm{mol}$<smiles></smiles>

5, $124.6^{\circ} \mathrm{C}$, $134.76 \mathrm{~kJ} / \mathrm{mol}$<smiles>Cc1cc(-c2ccccc2[I-]([O+])([O-])[O-])n[nH]1</smiles>

6, $168.9^{\circ} \mathrm{C}$, $2.52 \mathrm{~kJ} / \mathrm{mol}$<smiles></smiles>

$8,148.9^{\circ} \mathrm{C}$, $51.46 \mathrm{~kJ} / \mathrm{mol}$<smiles></smiles>

9, $198.8^{\circ} \mathrm{C}$ $76.36 \mathrm{~kJ} / \mathrm{mol}$<smiles></smiles>

$10,210.1^{\circ} \mathrm{C}$ $58.47 \mathrm{~kJ} / \mathrm{mol}$<smiles></smiles>

$11,193.9^{\circ} \mathrm{C}$, $64.81 \mathrm{~kJ} / \mathrm{mol}$<smiles></smiles>

$12,172.3^{\circ} \mathrm{C}$, $44.94 \mathrm{~kJ} / \mathrm{mol}$<smiles></smiles>

$13,159.2^{\circ} \mathrm{C}$, $73.52 \mathrm{~kJ} / \mathrm{mol}$<smiles></smiles>

$14,144.0^{\circ} \mathrm{C}$, $71.34 \mathrm{~kJ} / \mathrm{mol}$

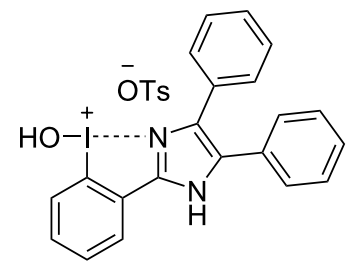

$15,118.9^{\circ} \mathrm{C}$, $39.70 \mathrm{~kJ} / \mathrm{mol}$

cyclic hydroxy(phenyl)- $\lambda^{3}$-iodanes<smiles>O=C1OI(O)c2ccccc21</smiles>

16, $267.3^{\circ} \mathrm{C}$, $65.03 \mathrm{~kJ} / \mathrm{mol}$

$17,195.7^{\circ} \mathrm{C}$ $134.49 \mathrm{~kJ} / \mathrm{mol}$

Figure 2: $T_{\text {peak }}$ and $\Delta H_{\text {dec }}$-values for a range of $\mathrm{N}$ - and O-substituted iodanes.

shows the lowest $\Delta H_{\mathrm{dec}}$ value among all investigated pseudocyclic iodanes $\left(\Delta H_{\mathrm{dec}}=2.5 \mathrm{~kJ} / \mathrm{mol}\right)$. Interestingly, the exothermal decomposition of $\mathbf{6}$ is superimposed by an endothermal melting process (Figure 3c). In direct comparison, indazole $\mathbf{8}$ is thermally less stable than 7 with a similar $\Delta H_{\text {dec }}$ value. The throughout higher thermal stability of pyrazoles and indazoles (6-8) in direct comparison to triazoles (2-5) is very likely connected with the lower $\mathrm{C} / \mathrm{N}$ ratio.

Benzimidazoles 9-11 showed increased $\Delta H_{\mathrm{dec}}$ values $(58.5-76.4 \mathrm{~kJ} / \mathrm{mol})$ in comparison with pyrazoles 6-8. Broad decomposition peaks (up to $14{ }^{\circ} \mathrm{C}$ peak width - see Supporting Information File 1) were observed at remarkable high $T_{\text {peak }}$ values (193.9-210.1 ${ }^{\circ} \mathrm{C}$ ). Following these results, it has been intriguing to analyze the influence of the heteroatom in the heterocyclic moiety on the thermal decomposition process. The change of one nitrogen atom to sulfur as in thiazole 12 resulted in a drastic decrease of $\Delta H_{\mathrm{dec}}$ to $44.9 \mathrm{~kJ} / \mathrm{mol}$. In contrast, oxazoles 13 and 14 both had a comparable $\Delta H_{\text {dec }}$ to 9 , however, these NHIs are thermally more labile $\left(T_{\text {peak }}=159.2\right.$ and 144.0 ${ }^{\circ} \mathrm{C}$ ). Compared to 9, diphenylimidazole-substituted NHI 15 exhibited a considerably lower $\Delta H_{\mathrm{dec}}$ value $(39.7 \mathrm{~kJ} / \mathrm{mol})$. Among the 1,3-azoles $\mathbf{1 5}$ is thermally the most labile one with a $T_{\text {peak }}$ of $118.9^{\circ} \mathrm{C}$. For an improved overview of the discussed $\Delta H_{\mathrm{dec}}$ values a graphical comparison sorted by the respective coordinating unit is given in Figure 4. 

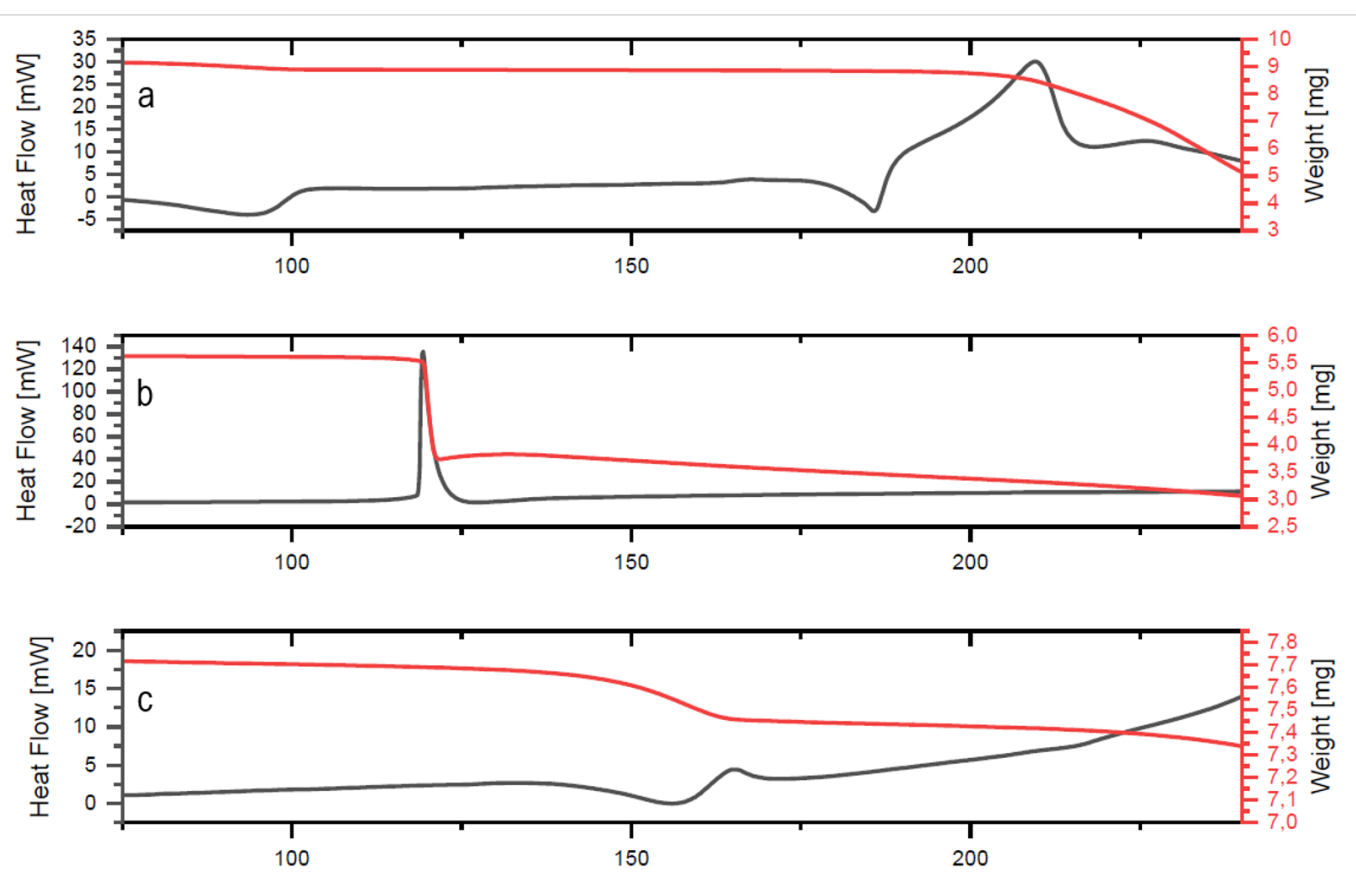

Figure 3: TGA/DSC curves of (a) benziodoxolone 1, (b) triazole 2 and (c) pyrazole 6.

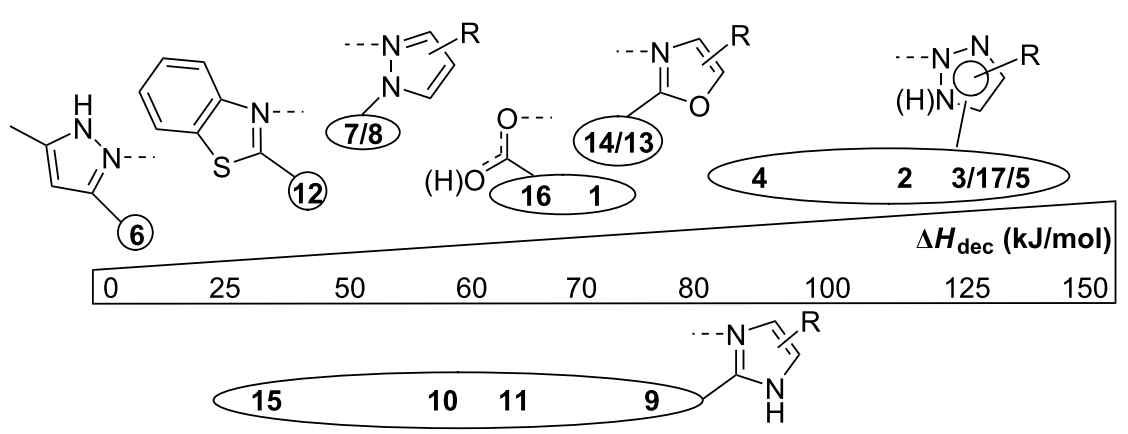

Figure 4: Decomposition enthalpy $\left(\Delta H_{\text {dec }}\right)$ scale for pseudocyclic tosylates 1-15 and cyclic iodoso species 16 and 17.

After obtaining decomposition energies and temperatures for these pseudocyclic NHIs, we were intended to relate these findings with their reactivity. For this purpose, we chose the oxidation of thioanisole at room temperature as the initial model reaction. This reaction shows quantitative conversion and therefore the reactivity of the substrates can be described by the ascertained reaction times [29]. However, because the reaction times differed widely a relative reactivity (based on the negative logarithm followed by normalization) was used for a better comparison (Figure 5).

As expected, the thermally least stable triazoles $\mathbf{2}-\mathbf{5}$ are also the most reactive iodanes in this model reaction, especially $\mathrm{N}$-substituted triazoles $\mathbf{4}$ and $\mathbf{5}$. In contrast, the reactivity of triazole $\mathbf{3}$ is comparable to that of benzoxazoles $\mathbf{1 3}$ and $\mathbf{1 4}$ as well as pyrazole $\mathbf{7}$ and indazole $\mathbf{8}$. In our view thiazole $\mathbf{1 2}$ is the best compromise in this regard since it is thermally even more stable than $\mathbf{7}$ and $\mathbf{8}$ with a significant higher reactivity. However, pyrazole 6 still shows a good reactivity in this model reaction with a concurrent outstanding thermal stability. If safety issues are a major concern, for example on a very large-scale synthesis, NHIs $\mathbf{6}$ or $\mathbf{1 2}$ should be the first choices. Except of $\mathbf{1 5}$ and 9, all diazoles are more stable and more reactive than the well-established benziodoxolone 1. It is also worth mentioning, that even the least stable NHI 5 can be still regarded as "safe" to use [31]. Further investigations are needed to fully capture the synthetic potential of these pseudocyclic NHIs.

We also evaluated the decomposition of cyclic hypervalent iodanes. Here, iodosobenzoic acid (IBA, 16) was chosen as an 


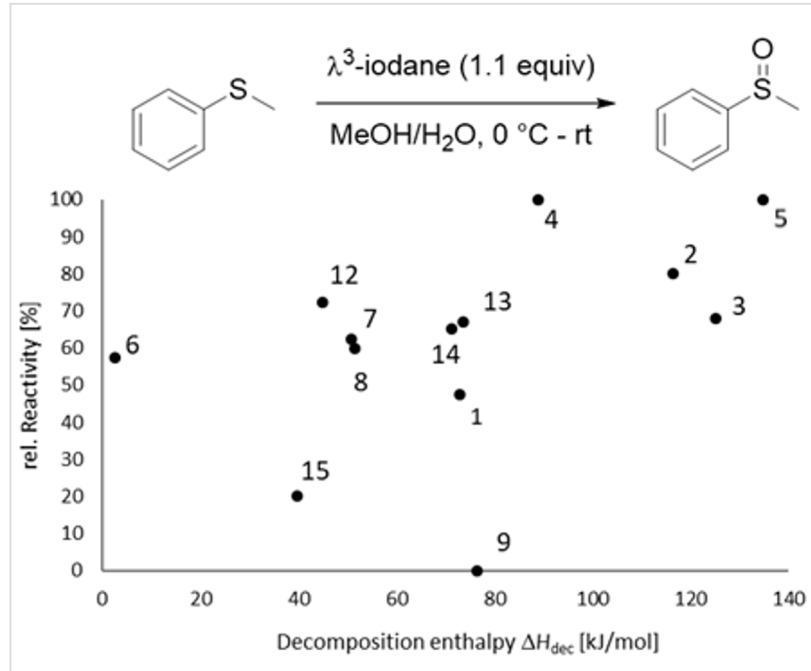

Figure 5: Correlation between the relative reactivity for pseudocyclic $\mathrm{NHIs}$ based on the reaction time in the oxidation of thioanisole with the corresponding decomposition enthalpy $\Delta H_{\text {dec }}$. Relative reactivity is based on the negative normalized logarithm. oxygen-bonded model substrate. In comparison to its pseudocyclic congener 1,16 demonstrated a higher $T_{\text {peak }}\left(267.3{ }^{\circ} \mathrm{C}\right.$ [19]) and a slightly lower $\Delta H_{\mathrm{dec}}(65.0 \mathrm{~kJ} / \mathrm{mol}$ vs $72.9 \mathrm{~kJ} / \mathrm{mol})$. Cyclic triazole $\mathbf{1 7}$ has a significantly higher $T_{\text {peak }}$ but also a higher $\Delta H_{\mathrm{dec}}$ compared to the corresponding pseudocycle 2 $(134.5 \mathrm{~kJ} / \mathrm{mol}$ vs $116.3 \mathrm{~kJ} / \mathrm{mol})$.

Besides pseudocyclic and cyclic hydroxy(aryl)- $\lambda^{3}$-iodanes, mesityl(phenyl)- $\lambda^{3}$-iodanes $\mathbf{1 8}-\mathbf{3 3}$ were systematically investigated by thermogravimetric analysis. Initially, the thermal decomposition of pseudocyclic diaryliodonium salts $\mathbf{1 8}$ and 19 was measured. For both salts, initial endothermic melting was followed by exothermal decomposition (Supporting Information File 1 and Figure 6).

Compared to hydroxy(phenyl)- $\lambda^{3}$-iodanes $\mathbf{1}$ and $\mathbf{2}$, the pseudocyclic diaryliodonium salts $\mathbf{1 8}$ and $\mathbf{1 9}$ show a significantly decreased $\Delta H_{\mathrm{dec}}$ from $72.9 \mathrm{~kJ} / \mathrm{mol}$ to $10.2 \mathrm{~kJ} / \mathrm{mol}$ for benziodoxolones 1 and 18 and from $116.3 \mathrm{~kJ} / \mathrm{mol}$ to $23.4 \mathrm{~kJ} / \mathrm{mol}$ for the

pseudocyclic mesityl(phenyl)- $\lambda^{3}$-iodanes

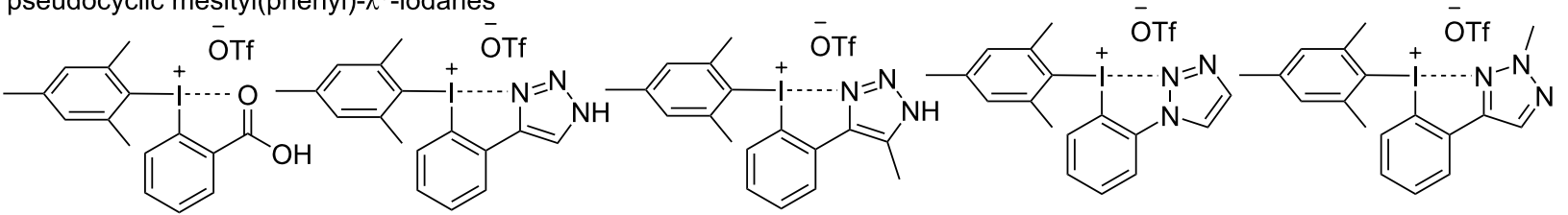

$18,202.1^{\circ} \mathrm{C}$, $10.19 \mathrm{~kJ} / \mathrm{mol}$

$19,158.9^{\circ} \mathrm{C}$, $23.37 \mathrm{~kJ} / \mathrm{mol}$<smiles></smiles>

24, $191.8^{\circ} \mathrm{C}$ $86.01 \mathrm{~kJ} / \mathrm{mol}$ $20,158.3^{\circ} \mathrm{C}$ $13.18 \mathrm{~kJ} / \mathrm{mol}$
21, $180.0^{\circ} \mathrm{C}$ $46.50 \mathrm{~kJ} / \mathrm{mol}$
22, $216.8^{\circ} \mathrm{C}$, $-29.81 \mathrm{~kJ} / \mathrm{mol}$<smiles></smiles>

23, $199.4^{\circ} \mathrm{C}$ $21.85 \mathrm{~kJ} / \mathrm{mol}$<smiles></smiles>

27, $227.6^{\circ} \mathrm{C}$, $37.67 \mathrm{~kJ} / \mathrm{mol}$<smiles></smiles>

$25,180.6^{\circ} \mathrm{C}$, $4.70 \mathrm{~kJ} / \mathrm{mol}$

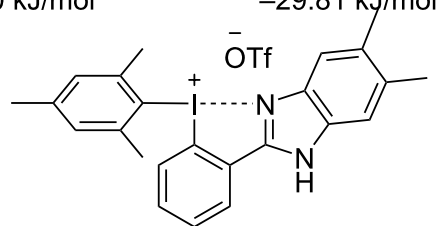

26, $219.5^{\circ} \mathrm{C}$, $32.98 \mathrm{~kJ} / \mathrm{mol}$<smiles></smiles>

28, $205.7^{\circ} \mathrm{C}$, $51.80 \mathrm{~kJ} / \mathrm{mol}$<smiles></smiles>

$29,200.6^{\circ} \mathrm{C}$

cyclic mesityl(phenyl)- $\lambda^{3}$-iodanes<smiles>Cc1cc(C)c(I2[IH]OC(=O)c3ccccc32)c(C)c1</smiles>

$30,227.3^{\circ} \mathrm{C}$ $85.85 \mathrm{~kJ} / \mathrm{mol}$

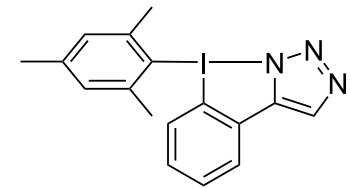

$31,226.9^{\circ} \mathrm{C}$, $98.34 \mathrm{~kJ} / \mathrm{mol}$

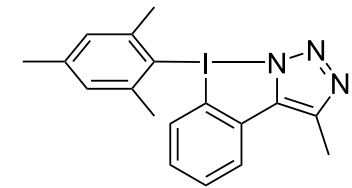

32, $210.8^{\circ} \mathrm{C}$ $141.13 \mathrm{~kJ} / \mathrm{mol}$

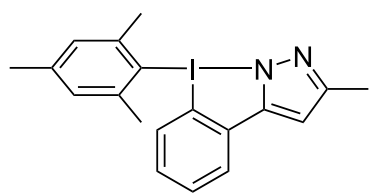

33, $201.1^{\circ} \mathrm{C}$ $122.66 \mathrm{~kJ} / \mathrm{mol}$

Figure 6: $T_{\text {peak }}$ and $\Delta H_{\text {dec }}$ values for a range of $\mathrm{N}$ - and O-substituted iodanes. 
triazole derivatives 2 and 19. The same trend of a higher thermal stability and lower $\Delta H_{\mathrm{dec}}$ for diaryliodonium salts compared the their hydroxy-substituted congeners can be observed for all other pseudocyclic $N$-heterocycle-substituted derivatives 20-29. Pyrazole 24 is the only exception. All investigated diaryliodonium salts can be defined as safe due to $T_{\text {peak }}$ values of usually above $180{ }^{\circ} \mathrm{C}$ and $\Delta H_{\mathrm{dec}}$ values of less than $50 \mathrm{~kJ} / \mathrm{mol}$. A graphical comparison of the discussed $\Delta H_{\mathrm{dec}}$ values for mesityl(phenyl)- $\lambda^{3}$-iodanes is given in Figure 7 . In comparison with Figure 4 it clearly shows that the relative stability of these heterocycle-stabilized diaryliodonium salts do not show the same trend as observed for the initially discussed hydroxy(phenyl) $-\lambda^{3}$-iodanes. In particular, the (pseudo)cyclic pyrazole derivatives $\mathbf{2 4}$ and $\mathbf{3 3}$ show a comparable high $\Delta H_{\mathrm{dec}}$ value.

These overall significant lower decomposition energies are in good agreement with published data in the field of reactivity and stability of hypervalent iodine compounds [32]. As another common key characteristic, the exothermic decomposition of diaryliodonium salts occurs during an endothermic melting process as shown in Figure 8. Only the phenylbenzimidazoles 26 and 27 do not show this apparent melting-associated endothermic effect. Interestingly, 22 shows a very unusual endothermal decomposition of $-29.81 \mathrm{~kJ} / \mathrm{mol}$.

Cyclic mesitylene derivatives $\mathbf{3 0}-\mathbf{3 3}$ have significantly increased $\Delta H_{\text {dec }}$ values. Their TGA/DSC curves reveal a decomposition behavior similar to the pseudocyclic hydroxy(phenyl)$\lambda^{3}$-iodanes with an exothermal decomposition without initial melting as exemplarily shown in Figure 9 for compound $\mathbf{3 2}$.

We can thus conclude that the formation of cyclic iodanes results in an undesired increase of $\Delta H_{\mathrm{dec}}$ value and therefore, their pseudocyclic precursors should be used whenever possible.

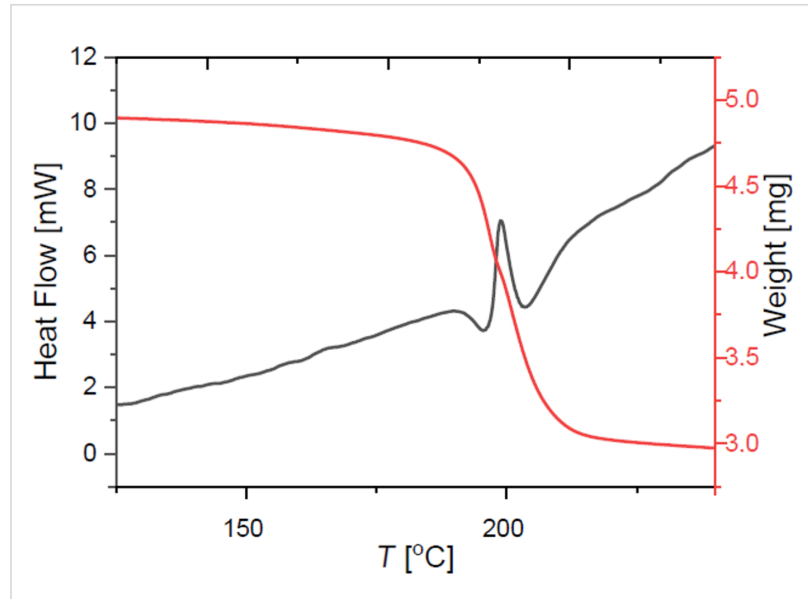

Figure 8: TGA/DSC curves for the benzimidazole based diaryliodonium salt 25.

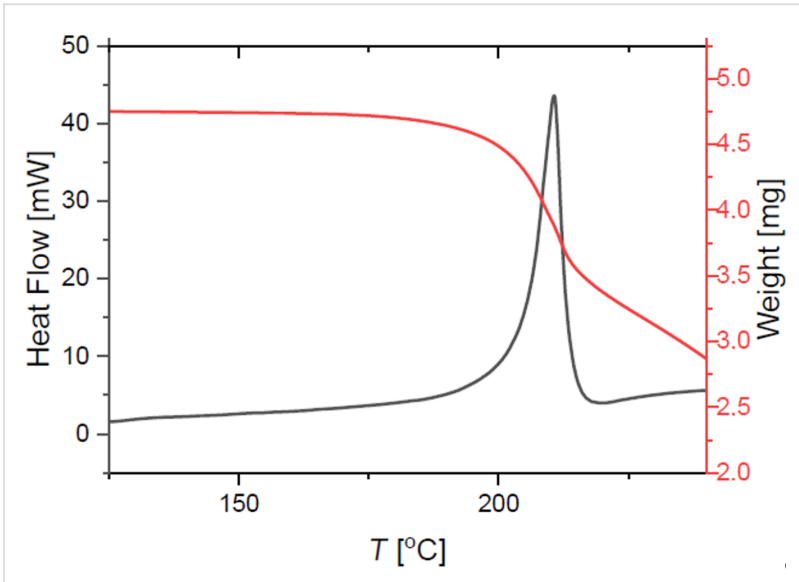

Figure 9: TGA/DSC curves for the cyclic triazole 32.

Finally, we investigated the decomposition products of one pseudocyclic (25) and one cyclic (33) diaryliodonium salt. Pseudocyclic salt 25 was heated to $185^{\circ} \mathrm{C}$ and the resulting oily

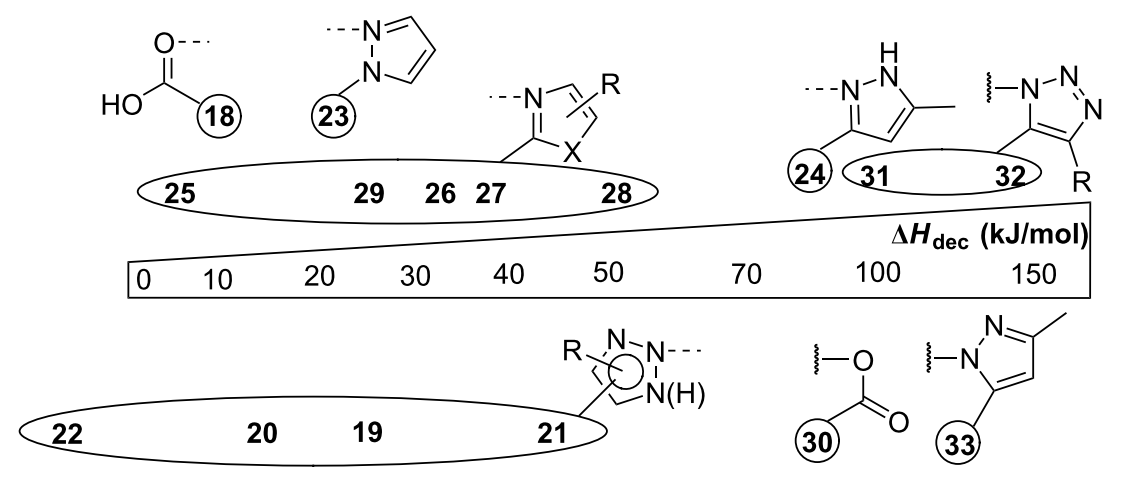

Figure 7: Decomposition enthalpy $\left(\Delta H_{\text {dec }}\right)$ scale for (pseudo)cyclic mesitylen(phenyl)- $\lambda^{3}$-iodanes 18-33. 
residue was analyzed by GC-MS (Scheme 1a). Besides dearylation to aryl iodide 25a we observed the formation of an $\mathrm{N}$-arylated product $\mathbf{2 5 \mathbf { b }}$ in significant amounts. In a similar experiment compound 33 was heated to $160{ }^{\circ} \mathrm{C}$ and $210{ }^{\circ} \mathrm{C}$ according to the two exothermic peaks observed in the TGA/DSC curve (see Supporting Information File 1). The resulting product mixture was further analyzed by TLC-MS. While at $160{ }^{\circ} \mathrm{C}$ no significant decomposition was visible, pronounced decomposition has been observed at $210^{\circ} \mathrm{C}$. The MS analysis revealed the formation of the $N$-arylated pyrazoles $\mathbf{3 3 a}$ and $\mathbf{3 3} \mathbf{b}$ as the main products (Scheme 1b).

Both decomposition studies let us conclude, that intermolecular $N$-arylation is the major decomposition pathway of (pseudo)cyclic $N$-heterocycle-stabilized mesityl(phenyl)- $\lambda^{3}$ iodanes.

\section{Conclusion}

Based on these comprehensive thermoanalytic studies we conclude that (pseudo)cyclic NHIs are throughout safe to use reagents with a sufficient thermal stability. Only the triazole derivatives $(\mathbf{2}, \mathbf{3}$, and $\mathbf{5})$ deserve common precautions due to the relatively narrow decomposition peak. In particular, benzothiazole- and pyrazole-substituted hydroxy(phenyl)- $\lambda^{3}$-iodanes (12 and 6-8) show an excellent relation between thermal stability and reactivity, in particular in direct comparison with wellknown benziodoxolones. We can also conclude that the pseudocyclic forms of aryl(phenyl)- $\lambda^{3}$-iodanes should be the reagents of choice as electrophilic aryl group transfer reagents. Thermal decomposition studies indicate that they should be potent electrophilic arene donors.

\section{Supporting Information}

\section{Supporting Information File 1}

Synthetic procedures as well as TGA/DSC curves and

NMR spectra for all investigated iodanes.

[https://www.beilstein-journals.org/bjoc/content/

supplementary/1860-5397-15-223-S1.pdf]

\section{Acknowledgements}

Funding by the Fonds der Chemischen Industrie (PhD scholarship to AB), Russian Science Foundation (grant No. 17-7320066) and GACR (19-24603Y) is gratefully acknowledged. TG/DTA for the compound 16 and GCMS measurements of thermal decomposition for the compound $\mathbf{2 5}$ were carried out using the core facilities of TPU's "Physical and chemical methods of analysis".

\section{ORCID ${ }^{\circledR}$ iDs}

Boris J. Nachtsheim - https://orcid.org/0000-0002-3759-2770

Pavel S. Postnikov - https://orcid.org/0000-0001-9713-1290

\section{Preprint}

A non-peer-reviewed version of this article has been previously published as a preprint https://doi.org/10.26434/chemrxiv.8964848.v1

\section{References}

1. Hypervalent lodine Chemistry. Wirth, T., Ed.; Topics in Current Chemistry, Vol. 373; Springer International Publishing: Cham, Switzerland, 2016. doi:10.1007/978-3-319-33733-3

(a)

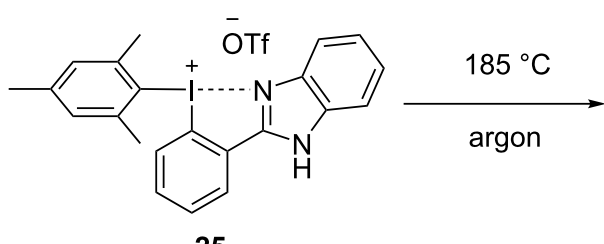

(b)

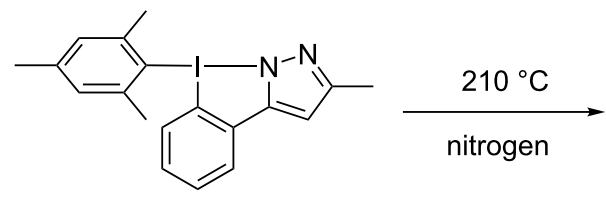

33

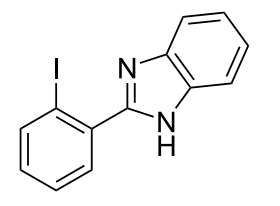

25a

$(\mathrm{m} / \mathrm{z}: 320.0)$<smiles>Cn1c(-c2ccccc2I)nc2ccccc21</smiles>

25b

( $m / z: 438.1)$

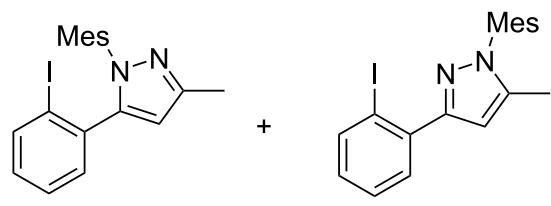

$33 a$

( $\mathrm{m} / \mathrm{z}: 402.1)$ 33b

( $m / z: 402.1)$ 
2. Yoshimura, A.; Zhdankin, V. V. Chem. Rev. 2016, 116, 3328-3435. doi:10.1021/acs.chemrev.5b00547

3. Boelke, A.; Finkbeiner, P.; Nachtsheim, B. J. Beilstein J. Org. Chem. 2018, 14, 1263-1280. doi:10.3762/bjoc.14.108

4. Grelier, G.; Darses, B.; Dauban, P. Beilstein J. Org. Chem. 2018, 14, 1508-1528. doi:10.3762/bjoc.14.128

5. Yusubov, M. S.; Zhdankin, V. V. Curr. Org. Synth. 2012, 9, 247-272. doi:10.2174/157017912799829021

6. Zhdankin, V. V. ARKIVOC 2009, No. i, 1-62. doi:10.3998/ark.5550190.0010.101

7. Dohi, T.; Kita, Y. Chem. Commun. 2009, 2073-2085. doi:10.1039/b821747e

8. Wirth, T. Angew. Chem., Int. Ed. 2005, 44, 3656-3665. doi:10.1002/anie.200500115

9. Moriarty, R. M. J. Org. Chem. 2005, 70, 2893-2903. doi:10.1021/j0050117b

10. Wirth, T. Synthesis 1999, 1271-1287. doi:10.1055/s-1999-3540

11. Stang, P. J.; Zhdankin, V. V. Chem. Rev. 1996, 96, 1123-1178. doi:10.1021/cr940424+

12. Hari, D. P.; Caramenti, P.; Waser, J. Acc. Chem. Res. 2018, 51, 3212-3225. doi:10.1021/acs.accounts.8b00468

13. Zhdankin, V. V.; Krasutsky, A. P.; Kuehl, C. J.; Simonsen, A. J.; Woodward, J. K.; Mismash, B.; Bolz, J. T. J. Am. Chem. Soc. 1996, 118, 5192-5197. doi:10.1021/ja954119x

14. Zhdankin, V. V.; Kuehl, C. J.; Krasutsky, A. P.; Bolz, J. T.; Mismash, B.; Woodward, J. K.; Simonsen, A. J. Tetrahedron Lett. 1995, 36, 7975-7978. doi:10.1016/0040-4039(95)01720-3

15. Charpentier, J.; Früh, N.; Togni, A. Chem. Rev. 2015, 115, 650-682. doi:10.1021/cr500223h

16. Katsoulos, G. A.; Lalia-Kantouri, M.; Varvoglis, A. Thermochim. Acta 1992, 197, 285-294. doi:10.1016/0040-6031(92)85027-s

17. Varvoglis, A. Chem. Soc. Rev. 1981, 10, 377. doi:10.1039/cs9811000377

18. Verma, V.; Singh, K.; Kumar, A.; Kumar, D. J. Therm. Anal. Calorim. 2013, 114, 339-344. doi:10.1007/s10973-012-2894-1

19. Fiederling, N.; Haller, J.; Schramm, H. Org. Process Res. Dev. 2013, 17, 318-319. doi:10.1021/op400035b

20. Dallaston, M. A.; Bettencourt, C. J.; Chow, S.; Gebhardt, J.; Spangler, J.; Johnston, M. R.; Wall, C.; Brusnahan, J. S.; Williams, C. M. Chem. - Eur. J. 2019, 25, 9614-9618. doi:10.1002/chem.201902036

21. Alazet, S.; Preindl, J.; Simonet-Davin, R.; Nicolai, S.; Nanchen, A.; Meyer, T.; Waser, J. J. Org. Chem. 2018, 83, 12334-12356. doi:10.1021/acs.joc.8b02068

22. Aertker, K.; Rama, R. J.; Opalach, J.; Muñiz, K. Adv. Synth. Catal. 2017, 359, 1290-1294. doi:10.1002/adsc.201601178

23. Xie, F.; Zhang, Z.; Yu, X.; Tang, G.; Li, X. Angew. Chem., Int. Ed. 2015, 54, 7405-7409. doi:10.1002/anie.201502278 Angew. Chem. 2015, 127, 7513.

24. Boppisetti, J. K.; Birman, V. B. Org. Lett. 2009, 11, 1221-1223. doi:10.1021/ol8029092

25. Hari, D. P.; Schouwey, L.; Barber, V.; Scopelliti, R.; Fadaei-Tirani, F.; Waser, J. Chem. - Eur. J. 2019, 25, 9522-9528. doi:10.1002/chem.201900950

26. Zhdankin, V. V.; Koposov, A. Y.; Su, L.; Boyarskikh, V. V.; Netzel, B. C.; Young, V. G. Org. Lett. 2003, 5, 1583-1586. doi:10.1021/ol0344523

27. Zhdankin, V. V.; Arbit, R. M.; McSherry, M.; Mismash, B.; Young, V. G. J. Am. Chem. Soc. 1997, 119, 7408-7409. doi:10.1021/ja971606z
28. Balthazor, T. M.; Godar, D. E.; Stults, B. R. J. Org. Chem. 1979, 44, 1447-1449. doi:10.1021/jo01323a018

29. Boelke, A.; Lork, E.; Nachtsheim, B. J. Chem. - Eur. J. 2018, 24, 18653-18657. doi:10.1002/chem.201804957

30. Vlasenko, Y. A.; Postnikov, P. S.; Trusova, M. E.; Shafir, A.; Zhdankin, V. V.; Yoshimura, A.; Yusubov, M. S. J. Org. Chem. 2018, 83, 12056-12070. doi:10.1021/acs.joc.8b01995

31. UN/SCETDG/53/INF.17. https://www.unece.org/fileadmin/DAM/trans/doc/2018/dgac10c3/UN-SC ETDG-53-INF17e.pdf (accessed Sept 24, 2019).

32. Zhdankin, V. V. Hypervalent lodine Chemistry; John Wiley \& Sons Ltd.: Chichester, United Kingdom, 2013. doi:10.1002/9781118341155

\section{License and Terms}

This is an Open Access article under the terms of the Creative Commons Attribution License (http://creativecommons.org/licenses/by/4.0). Please note that the reuse, redistribution and reproduction in particular requires that the authors and source are credited.

The license is subject to the Beilstein Journal of Organic Chemistry terms and conditions: (https://www.beilstein-journals.org/bjoc)

The definitive version of this article is the electronic one which can be found at: doi:10.3762/bjoc. 15.223 